\title{
The key elements of cultural intelligence as a driver for digital leadership success
}

\author{
René Rüth ${ }^{1}\left[\right.$ D $\cdot$ Torsten Netzer $^{1}$
}

Received: 19 August 2019 / Accepted: 17 December 2019 / Published online: 8 January 2020

(c) The Author(s) 2019

\begin{abstract}
In today's globalized economy, being successful in an industry almost necessarily implies an international approach of doing business. Restricting one's economic activities to the domestic market will ultimately lead to disadvantages in comparison to multinational companies which are able to grow rapidly in emerging markets. The digital transformation further increases the possibilities for companies that operate across national borders and has become the enabler to serve customers all around the world and increase the responsiveness of the business in all areas. At the same time this fact further increases the pressure on companies driving global hypercompetition. In order to survive in this globalized, hypercompetitive world companies need to embrace the opportunity and internationalize their business. One of the main tools for successfully operating in different business cultures is the ability to manage the workforce in an international environment. Not only the foreignness of the new markets a company is operating in but also the different cultures of the team members are challenging modern leaders. The concept of cultural intelligence (CQ) provides the toolset to manage a diverse workforce from various cultural backgrounds within one organizational framework. CQ will be explained and its importance for digital leadership will be discussed. Especially when communication across borders and interaction between members and customers from different cultural background happens in real-time it is important to understand and interpret behavior correctly and communicate or act with a high and flexible cultural awareness. This is where the paper will line out that CQ has become an important tool for leadership success in a digital world and will explain the key elements of CQ with the highest influence on leadership in this digital setting.
\end{abstract}

Keywords Cultural intelligence $\cdot$ Leadership $\cdot$ Intercultural management $\cdot$ Digital transformation

\section{Introduction}

Globalization is still the name of the game. Despite recent trade disputes provoked by the Trump administration, the future of global welfare is seen in an increase rather than a decrease of global economic interdependence. Multinational corporations dominate most industries and there are only a few highly specialized markets in which medium sized companies can claim to be market leaders (Büchler 2018). The digital transformation adds up to this development. New digital business models emerge thanks to AI, the internet of things and Big Data (Mikfeld 2016). Their

René Rüth

rene.rueth@institut-mec.de

1 IMEC Institute for Management Education and Culture, Weismüllerstr. 45/Campus Osthafen, 60314 Frankfurt am Main, Germany effects on existing markets are often extremely disruptive due to the massive scaling that digital businesses can perform. Once an online platform for a new digital service has been established for one country it can easily be applied to another, often causing havoc in each domestic market it is being adopted to Eder (2017). One of the conclusions this development leads to is quite simply the fact that internationalization is key in today's world of globalized and digitized economy. Without international if not global business activities resounding market success will hardly last in the age of digital transformation. Therefore, and based on the fact that our workforce becomes more diverse any digital leadership must be thought of as intercultural leadership. Cultures intermingle and proficiency in the ability of working across cultural boarders is crucial for leaders who inevitably work with employees and customers from various cultural backgrounds (Kreutzer et al. 2017). The effects for 
leadership that result from this intercultural field of attention will be further scrutinized in the next section.

\section{The meaning of leadership}

In order to understand why leadership is deeply dependent on cultural issues a distinction between leadership and management needs to be drawn. A somewhat broad-brushed definition states: Leaders are concerned with human beings while managers are occupied with numbers (Kotter 1990). A more recent differentiation defines leaders as changing companies while managers ought to keep the house clean and running (Algahtani 2014). Leaders bring up ideas, they motivate people to cope with uncertainty and insecurity. Leaders frame the narratives and goals of corporations. Managers, on the other hand, execute decisions daily. They run operations, motivate people to give their best every day, assign tasks, monitor operations and act for the purpose of the company's economical well-being.

Another angle on the difference between leadership and management can be time (Yukl 2010). Managers are focused on the present: What revenue does each division of the company generate at the moment? To which degree will it change in the recent future if which factor is to be manipulated and adjusted? Managers take responsibility for the present economic state of a company. Leaders differ from them by their focus on the future (Kotter 1990). They reckon about the next 5-10 years or even further ahead e.g. many founders and owners of family businesses who built a company for the next generations of their family. Once you focus on a future that is far away, numbers become less and less reliable. It is just not very helpful if you want to count profits in 10 years if you do not even know if it will be by manufacturing cars, coding software, helping cities not to infrastructurally collapse or all of this at once. The future has always been quite unknown until it became the present and a leader's job description does not entail the gift of foresight. However, leaders need to be as good as possible in looking ahead which is to say they must know how to gather the according information, how to talk to those who know better than they do and how to bind all this together into compelling ideas that impress customers and motivate employees for doing their best everyday (Kotter 1990).

\section{Digital transformation demands leadership}

These features of leaders reveal that leadership is of particular importance in times of change. As long as a company's business model is unchallenged by competitors and customers preferences, having good leadership might not be crucial for the survival of a company. However, this is where the digital transformation comes into play. Today, basically all companies are faced with revolutionary changes in (1) the means by which they run their businesses, (2) the goals which define their business models, and (3) the social world they are doing business in.

1. The digitization of business processes allows historically unprecedented monitoring and control of virtually every aspect. Big data and artificial intelligence support companies in optimizing every step of their processes-as long as these steps can be measured and then grasped by algorithms (Davenport 2018). This option massively supports the task of managers. However, as AI is not ready yet to tackle with the many not countable aspects that leaders are to ponder on, the digitization of business processes opens up possibilities that do not make sense by themselves but only with support of human minds one of which is that of the leader's.

2. One of a leader's most important task consists of the development of the business model. Technological advancements driven by the digital transformation cause countless new business possibilities to evolve. Most of which are having very disruptive effects on established companies and their business models. Options like big data and AI which affect business processes have even more impact on business models (Wodecki 2019). Leaders are needed to clarify and to decide whether their own company's goals will promise sufficient revenue in the future. If not, new ideas for economic success need to be developed. This process must be initiated and accompanied by business leaders (Mintzberg et al. 1998). Often, it will eventually be them to take responsibility for the outcome of such change processes.

3. Which of the new business models best to thrive for will heavily depend on the social change, the digitized society will be going though. Getting to understand which changes will take place requires an equal understanding of the effects that new media and communication devices will have on the social fabric of today's life. This will also affect the customers' needs companies can reasonably hope to inflame. In case of leaders, these social changes must be understood as well as possible (Burgartz and Krämer 2016). Good leadership will gather information and transfer them to people who understand their part of the changing process. Eventually, everything must be combined to picture the company's future which then helps to frame what the company should be doing in order to secure if not improve its market position-in a global marketplace.

This must be transferred into a leadership and management framework which is able to deal with the fact that 
our workforce is globalized and diverse by all means. It needs to enable an efficient and effective way of achieving the goals which have been defined. One of the concepts developed to achieve these goals is called Führung 4.0 (Schwarzmüller et al. 2017). It defines the most important changes of the traditional relationship between company leaders and employees. Among them the participation of employees and the democratization of decision making are most prominent. Raising demands for competences and the importance of agility are also crucial. Thus, digitalization and globalization have changed the whole leadership and management context. Leaders and managers require a different solution to this challenge.

\section{Leaders need intercultural tools}

All three tasks today's companies are confronted with by the digital transformation can only be dealt with interculturally (Levy et al. 2016). Digital business models transcend national boundaries due to their potency of scaling: The power of many digital services lies in the possibility to be easily applied to an unlimited number of customers once the core service has been established (Meyer 2016). Combined with the large amounts of data gathered from their customers, digitized services can be improved in such a way that they quickly become indispensable for their clients. This deepens the intercultural nature of the digital transformation even further.

Since it is obvious to which degree digitization fosters intercultural connectedness, digital leadership needs tools and means to successfully operate in intercultural environments. Some of the plentiful tasks leadership has to manage due to its intercultural embedding are the following (Pfeifer and Jackson 2008):

- Communicating successfully and efficiently with employees from various cultures.

- Understanding needs and requirements from culturally different customers.

- Creating leadership ideas that are appealing to stakeholders from many countries.

- Training employees to better deal with cultural heterogeneity.

- Choosing managers that will successfully set up new branches in foreign cultures.

All these tasks can be mastered by one of the most powerful tools for dealing with intercultural situations: cultural intelligence.

\section{Cultural intelligence and its key elements}

Cultural intelligence (CQ) is a powerful business tool for predicting managerial success in an intercultural environment. Its predictive accuracy has been developed since 2003 (Earley and Ang 2003) and proven by dozens of studies with tens of thousands of participants (Ang et al. 2015). Its statistical rigor has provided evidence to the theoretical framework that builds its base. This framework allows not only to predict intercultural success but also to understand the decisive abilities by which people feel at ease in intercultural situations ( $\mathrm{Ng}$ et al. 2012). Therefore, CQ also allows to discover flaws, to train employees and to adjust organizational processes in order to help multinationals and any digitized and internationally interconnected company to thrive. What does the theoretical basis of CQ consists of that makes it such a powerful tool for intercultural leadership?

\subsection{Multidimensional approach to intelligence}

CQ's ability of measuring and training intercultural attitudes and sensibilities as well as predicting individual intercultural success is based on a multidimensional approach to intelligence. CQ differs from the classic concept of intelligence which proposes a g-factor that is spread across the population in a Gauss distribution and which indicates the probability of educational and societal success over the span of lifetime. The talent to CQ is partly determined by social and genetic conditions but in opposition to the concept of general intelligence it can be trained and improved (Rockstuhl et al. 2011). The reason for this lies in the multidimensional approach to intelligence.

The CQ concepts adopts research done by Robert J. Sternberg. According to his model, intelligence should be conceived as three dimensional. Hence, the genetically determined factor of analytical intelligence defines only one dimension. The main reason why Sternberg enlarges the initial approach to general intelligence is because he is interested in successful intelligence. Sternberg defines: "I view intelligence in context as consisting of purposive adaptation to, shaping of, and selection of real-world environments relevant to one's life" (Sternberg 2009, 37). The three dimensions implicit in this definition are: analysis, adaptation, and experience. So, successfully intelligent is a person not only by being good in filling out intelligence test but rather by acting successfully in real life. What's special about the real life: Here, one is confronted with hardly predictable environments in which adaptation to the environmental conditions plays an equally important part as does the smart manipulation of this environment. 


\subsection{Four dimensions of CQ}

For CQ, the three dimensions of Sternbergs approach have been adjusted and, in a way, simplified in order to fit the purpose of intercultural business success. They can be precisely measured but they do not cover the full-fledged horizon anymore that Sternberg wanted to scrutinize with his three dimensions and eight according components. The four dimensions of CQ are more appropriate when it comes to their implementation in real life business processes. The definition, on which these dimensions are based, says CQ is the "capability to function effectively in intercultural contexts" (Ang et al. 2015, 274). As simple as this definition might sound, it contains some profound features which can be further explained. The term 'function' indicates that $\mathrm{CQ}$ focuses on practical purposes. In accordance with the complex models of intelligence as proposed by Sternberg, CQ measures not only potentiality but actual success. To function in a new environment indicates exactly this practical ability to get along well with new cultures. The environment of new cultures is included in the term 'intercultural contexts'. What is particularly important, is that CQ does not only explain probable behavior in completely new cultures but in any situation in which cultural differences become striking. Thus, it also helps to understand why certain people are more successful when communicating and interacting with people of different religion or social class within their national country (Van Dyne et al. 2012). Sometimes cultural differences become vital when you move in your neighborhood, sometimes when you leave the county, cross a national border or fly to another continent. In any case, CQ helps to better understand why some people are more successful in coping with such situations than others. Eventually, speaking of CQ as a 'capability' does entail that there are innate as well as acquired skills involved in cultural intelligence. This is good news for leaders because CQ can be trained and purposefully improved. Even though CQ shares some similarities with cognitive concepts of intercultural competence such as Deardorff's pyramid model (Spitzberg and Changnon 2009), the concept of CQ takes as broader approach and encompasses more dimensions than the competence models. This is particularly the case due to the measuring of motivational attitudes by CQ. As a concept, CQ does not only gather information about one's cognitive abilities. Its aim is to evaluate the probability by which a future expatriate will be successful. This goes beyond the scaling of competences and includes attitudes and mindsets, too. Four different dimensions of capabilities make sure that CQ can keep what it promises. These four dimensions encompass (1) cognitive, (2) metacognitive, (3) motivational and (4) behavioral abilities. Only together they ensure intercultural success.
1. The cognitive dimension gathers knowledge about rules and norms of a particular culture. This encloses the legal and the economic system as well as the rules that determine the use of language, religious values, rules of art, marriage or body language (Ang et al. 2007). All of this can and must be learned by foreigners and intercultural training has been focusing on these issues for decades.

2. Metacognition covers the ability to learn and to correctly add or replace your cultural knowledge wherever it may be incomplete or just wrong. Thus, metacognition adds the necessary skill without which cognition cannot be properly acquired. It could even be said that metacognitive abilities comprise most trenchantly what is commonly known as intelligence (Ang et al. 2007). These capabilities are made of sensitivity, empathy and the ability to being self-reflexive. Metacognitive intelligent people know how to apply their knowledge and where to broaden their knowledge by learning from others. They also know the ways to efficiently deepen their knowledge by observing, studying or just testing new behavior. Furthermore, they have a good feeling about which characteristics in people's behavior are individually, socially or culturally determined (Baghat 2006).

3. The motivational dimension includes the will to leave familiar patterns of behavior behind in order to get entirely immersed in new situations. It measures a person's passion for moving and diving into a different culture. It also implies the confidence and self-esteem for dealing with the unpredictable situations which are likely to appear in the foreign culture. This qualifies the disposition to cope well with events of stress and unease. The will to adapt to a new culture is also part of this so called drive dimension because without adaptation, business success is rather unlikely to happen (Ang et al. 2011).

4. In order to truly approach new cultures, culturally intelligent people have to change their behavior. All abilities to reflect and to learn, all motivation and confidence do not pay off if a person is not able to really change what she is doing. This is covered by the fourth and final dimension of CQ. To give but one example, a very reasonable strategy would be to slow down one's communication in order not to commit severe mistakes and to be attentive for the counterpart's reaction.

\subsection{CQ determines business success}

The four dimensions of CQ are not only easy to understand they are also easy to assess by just a short questionnaire of 37 questions. Despite their simplicity they are astonishingly informative. Comprehensive research studies have been conducted in order to determine the degree to which CQ can predict business success. The results were stunning. 
Studies showed that CQ makes emotional fatigue during working abroad less likely (Tay et al. 2008), the same could be shown for the likeliness of a cultural shock (Chen et al. 2011) or the tendency to change job (Huff 2013). A higher CQ resulted in better leadership outcome (Groves and Feyerherm 2011). Also, CQ predetermined more successfully the personal as well as professional success abroad than other variables like international experience, language skills, personal traits or general intelligence (Ang et al. 2015). People with a higher amount of CQ established trust to people from different cultures more easily than people with a lower degree (Rockstuhl and Ng 2008).

Studies even checked alternative correlations and showed that CQ does not affect the degree to which participants trusted people from their own culture. Furthermore, intercultural sales success which is larger for people with higher CQ does not lead to higher sales of these people in general (Chen et al. 2012). Thus, people with higher CQ are not generally better in doing business but only when doing business with people from a different culture ( $\mathrm{Ng}$ et al. 2012).

\section{Conclusion}

CQ and its key elements of knowledge, motivation and behavioral control drive leadership success. CQ helps leaders to purposefully improve their own capabilities of cultural intelligence by evaluating their flaws and by training them respectively. Additionally, with CQ leaders know how to choose the right people for further improving the organization in the globalized and digitized environment on all levels. They can measure whose success as a company representative abroad will be most likely. Since CQ has been tested to many traits and behavioral features, it could be revealed that culturally intelligent people tend to negotiate more cooperatively (Imai and Gelfand 2010). They are personally more receptive (Ang et al. 2006), open to share and advance their ideas with people from different cultures (Ward and Fischer 2008). Even though the concept has been criticized as neoliberal and Eurocentric, this does not seem to be a particular flaw of CQ because it shares this objection with basically all empirical accounts to intercultural analysis in economics (Dutta and Dutta 2013).

Thanks to its features, CQ is a concept that helps to discover and subsequently satisfy customers' and employees' needs across cultural boundaries in a world that never sleeps and where constant communication and dialogue with stakeholders from diverse cultural backgrounds is mandatory to succeed. In today's digital revolution, successful leadership and management is a result of profound knowledge in the means of how businesses are run, the goals defining the business models and the social environment of the business. In this world digital leadership uses CQ to enable an efficient and effective way of collaboration reducing transactional costs to further improve the likelihood of survival of the company. Under these digital conditions, CQ is vital for planning, communicating, understanding, leading across cultural boundaries.

Open Access This article is licensed under a Creative Commons Attribution 4.0 International License, which permits use, sharing, adaptation, distribution and reproduction in any medium or format, as long as you give appropriate credit to the original author(s) and the source, provide a link to the Creative Commons licence, and indicate if changes were made. The images or other third party material in this article are included in the article's Creative Commons licence, unless indicated otherwise in a credit line to the material. If material is not included in the article's Creative Commons licence and your intended use is not permitted by statutory regulation or exceeds the permitted use, you will need to obtain permission directly from the copyright holder. To view a copy of this licence, visit http://creativecommons.org/licenses/by/4.0/.

\section{References}

Algahtani A (2014) Are leadership and management different? A review. J Manag Policies Pract 2(3):71-82

Ang S, Van Dyne L, Koh CSK (2006) Personality correlates of the four factor model of cultural intelligence. Group Organ Manag 31:100-123. https://doi.org/10.1177/1059601105275267

Ang S, Van Dyne L, Koh C, Ng KY, Templer KJ, Tay C, Chandrasekar NA (2007) Cultural intelligence: Its measurement and effects on cultural judgment and decision making, cultural adaptation, and task performance. Manag Organ Rev 3:335-371. https://doi.org/ 10.1111/j.1740-8784.2007.00082.x

Ang S, Van Dyne L, Tan ML (2011) Cultural Intelligence. In: Sternberg RJ, Kaufman SB (eds) The Cambridge Handbook of Intelligence. Cambridge University Press, New York, pp 582-602

Ang S, Van Dyne L, Rockstuhl T (2015) Cultural Intelligence: Origins, conceptualization, evolution and methodological diversity. In: Gelfand M, Chiu CY, Hong YY (eds) Handbook of advances in culture and psychology, vol 5. Oxford University Press, New York, pp 273-323

Baghat RS (2006) Reviewed work(s): cultural intelligence: individual interactions across cultures by P. Christopher Earley and Soon Ang; Working across Cultures by John Hooker. Acad Manag Rev 31(2):489-493. https://doi.org/10.5465/amr.2006.20208695

Büchler J-P (ed) (2018) Fallstudienkompendium Hidden Champions: Innovationen für den Weltmarkt. Springer Gabler, Wiesbaden

Burgartz T, Krämer A (2016) Measures to understand and control customer relationship and loyalty. In: Mack O, Khare A, Krämer A, Burgartz T (eds) Managing in a VUCA World. Springer International, Cham, pp 99-114

Chen AS, Lin Y, Sawangpattanakul A (2011) The relationship between cultural intelligence and performance with the mediating effect of culture shock: a case from Philippine laborers in Taiwan. Int J Intercult Relat 35:246-258. https://doi.org/10.1016/j.ijint rel.2010.09.005

Chen X, Lui D, Portnoy R (2012) A multilevel investigation of motivational cultural intelligence, organizational diversity climate, and cultural sales: evidence from U.S. Real Estate Firms. J Appl Psychol 97:93-106. https://doi.org/10.1037/a0024697

Davenport TH (2018) The AI Advantage: How to Put the Artificial Intelligence Revolution to Work. MIT Press, Cambridge, London 
Davidson JE, Downing CL (2000) Contemporary Models of Intelligence. In: Sternberg RJ (ed) Handbook of intelligence. Cambridge University Press, Cambridge, pp 34-49

Dutta MJ, Dutta D (2013) Multinational going cultural: a postcolonial deconstruction of cultural intelligence. J Int Intercult Commun 6(3):241-258. https://doi.org/10.1080/17513057.2013.776094

Earley PC, Ang S (2003) Cultural intelligence: individual interactions across cultures. Stanford University Press, Palo Alto

Eder M (2017) Digitale Evolution: Wie die digitalisierte Ökonomie unser Leben, Arbeiten und Miteinander verändern wird. Springer Gabler, Wiesbaden

Groves KS, Feyerherm AE (2011) Leader cultural intelligence in context: testing the moderating effects of team cultural diversity on leader and team performance. Group Organ Manag 36:535-566. https://doi.org/10.1177/1059601111415664

Huff CK (2013) Language, cultural intelligence and expatriate success. Manag Res Rev 36(6):596-612. https://doi.org/10.1108/01409 171311325750

Imai L, Gelfand MJ (2010) The culturally intelligent negotiator: the impact of cultural intelligence (CQ) on negotiation sequences and outcomes. Organ Behav Hum Decis Process 112:83-98. https:// doi.org/10.1016/j.obhdp.2010.02.001

Kotter JP (1990) A force for change: How leadership differs from management. The Free Press, New York

Kreutzer RT, Neugebauer T, Pattloch A (2017) Digital business leadership: digitale Transformation-Geschäftsmodell-Innovationagile organisation — change-management. Springer Gabler, Wiesbaden

Levy O, Peiperl MA, Jonsen K (2016) Cosmopolitanism in a globalized world: an interdisciplinary perspective. Adv Global Leadersh 9:281-323. https://doi.org/10.1108/S1535-120320160000009009

Meyer J-U (2016) Digitale disruption: Die nächste Stufe der Innovation. BusinessVillage, Göttingen

Mikfeld B (2016) Zur Einführung: Trends, Diskurse, Klärungsbedarfe. In: Bundesministerium für Arbeit und Soziales (ed) Werkhefte 01: Digitalisierung der Arbeitswelt. Berlin, pp 16-20

Mintzberg H, Ahlstrand B, Lampel J (1998) Strategy safari: a guided tour through the wilds of strategic management. Free Press, New York

Ng KY, Van Dyne L, Ang S (2012) Cultural intelligence: a review, reflections, and recommendations for future research. In: Ryan AM, Leong FTL, Oswald F (eds) Conducting multinational research projects in organizational psychology. American Psychological Association, Washington, DC, pp 29-58
Pfeifer D, Jackson B (2008) Cross-cultural leadership. In: Marturano A, Gosling J (eds) Leadership: the key concepts. Routledge, London, pp 32-35

Rockstuhl T, Ng KY (2008) The effects of cultural intelligence on interpersonal trust in multicultural teams. In: Ang S, Van Dyne L (eds) Handbook of cultural intelligence: theory, measurement and applications. Routledge, Abingdon, New York, pp 206-220

Rockstuhl T, Seiler S, Ang S, Van Dyne L, Annen H (2011) Beyond general intelligence (IQ) and emotional intelligence (EQ): the role of cultural intelligence (CQ) on cross-border leadership effectiveness in a globalized world. J Soc Issues 67:825-840. https://doi. org/10.1111/j.1540-4560.2011.01730.x

Schwarzmüller T, Brosi P, Welpe IM (2017) Führung 4.0 -Wie die Digitalisierung Führung verändert. In: Hildebrandt A, Landhäußer W (eds) CSR und Digitalisierung: Der digitale Wandel als Chance und Herausforderung für Wirtschaft und Gesellschaft. Springer Gabler, Berlin, pp 617-628

Spitzberg BH, Changnon G (2009) Conceptualizing Intercultural Competence. In: Deardorff DK (ed) The SAGE Handbook Intercultural Competence. SAGE, Thousand Oaks, pp 5-52

Sternberg RD (2009) Toward a Triarchic Theory of Human Intelligence. In: Kaufman JC, Grigorenko EL (eds) The essential Sternberg: essays on intelligence, psychology, and education. Springer Publishing, New York, pp 33-70

Tay C, Westman M, Chia A (2008) Antecedents and consequences of cultural intelligence among short-term business travelers. In: Ang S, Van Dyne L (eds) Handbook of cultural intelligence: theory, measurement and applications. Routledge, Abingdon, New York, pp 126-144

Van Dyne L, Ang S, Ng KY, Rockstuhl T, Tan ML, Koh C (2012) Sub-dimensions of the four factor model of cultural intelligence: expanding the conceptualization and measurement of cultural intelligence (CQ). Soc Pers Psychol Compass 6:295-313. https ://doi.org/10.1111/j.1751-9004.2012.00429.x

Ward C, Fischer R (2008) Personality, cultural intelligence, and intercultural adaptation. In: Ang S, Van Dyne L (eds) Handbook of cultural intelligence: theory, measurement and applications. Routledge, Abingdon, New York, pp 159-176

Wodecki A (2019) Artificial intelligence in value creation: improving competitive advantage. Palgrave Macmillan, Cham

Yukl G (2010) Leadership in organizations, 7th edn. Person, Upper Saddle River 